Thorax (1974), 29, 138.

\title{
Pulmonary blastoma : a case report
}

\author{
K. MADHUSUDANA RAO, R. P. GUPTA, P. B. DAS, \\ STANLEY JOHN, and A. WALTER

\begin{abstract}
Departments of Thoracic and Cardiovascular Surgery, and Pathology, Christian Medical College and Hospital, Vellore, India
\end{abstract}

\begin{abstract}
Rao, K. M., Gupta, R. P., Das, P. B., John, S., and Walter, A. (1974). Thorax, 29, 138-141. Pulmonary blastoma. A case report of a pulmonary blastoma is presented. A tumour was suspected at surgery and on histological examination this proved to be a pulmonary blastoma. A short review of the histogenesis and methods of treatment is given.
\end{abstract}

Pulmonary blastoma is the least common of all tumours of the lung. This histological entity was first recognized in 1952 . To date only 19 cases have been reported in the literature. There is considerable controversy regarding its histogenesis which has not yet been settled. The purpose of this communication is to present a case of pulmonary blastoma that we recently encountered.

\section{CASE REPORT}

Mrs. K., a 30-year-old woman, was admitted to hospital on account of pain in the posterior part of the right lower chest of 30 days' duration. The pain was episodic, radiating down the intercostal spaces and not aggravated by cough or respiratory excursions. She was afebrile and had no cough. There was no weight loss. Her physician had diagnosed a loculated effusion in the right chest from the radiograph. Two attempts at thoracentesis were made. It was reported that clear fluid was aspirated but this was not definitely documented. Before the onset of this illness she was in good health.

At the time of admission her general condition was satisfactory. There was no clubbing. The trachea was central and there was no mediastinal shift. The percussion note was impaired and vocal fremitus and resonance were decreased markedly at the right base. The breath sounds were decreased on the posterior aspect of the lower part of the right hemithorax. Other systems were normal. The white cell count was $8,500 / \mathrm{mm}^{3}$, with $72.0 \%$ neutrophils, $8.0 \%$ eosinophils, and $20.0 \%$ lymphocytes. The erythrocyte sedimentation rate was not raised. Casoni's test was negative. The chest radiograph (Fig. 1) showed a large, homogeneous, well-defined mass in the region of the right lower lobe. The

Requests for reprints: Dr. Stanley John, Department of Thoracic and Cardiovascular Surgery, Christian Medical College and Hospital, Vellore-632004, India costophrenic angle was not blunted. The lateral film showed that the mass was occupying the right lower lobe and, in comparison with the chest film taken one month before her present admission, the mass appeared to have increased in size. Bronchoscopy was not helpful.

Exploratory thoracotomy revealed a large, wellencapsulated tumour, measuring $15 \times 10 \times 5 \mathrm{~cm}$, occupying the right lower lobe. There was no fluid in the pleural cavity. The tumour was not adherent to the parietes nor to the upper lobe. The interlobar fissure was not obliterated. There were large, dilated, tortuous veins coursing over the tumour, which felt rather heavy. There were no palpable mediastinal lymph nodes. A right lower lobectomy was performed. She had an uneventful postoperative course and was discharged in good condition. She has been followed up for a period of three months and is in good health. The chest film taken three months after surgery revealed no abnormality.

MACROSCOPIC EXAMINATION The lower lobe was replaced by a large mass weighing $630 \mathrm{~g}$ and measuring $15 \times 12 \times 6.5 \mathrm{~cm}$. The mass was partly cystic and partly solid and was well encapsulated; $\rightarrow$ there were large vessels coursing over it. A fringe of lung tissue was present with thickened pleura $\tilde{N}$ overlying it and there were many congested blood o vessels. The cut surface showed that the mass was $N$ whitish and spongy with necrotic and haemorrhagic $\underset{\mathrm{N}}{\mathrm{N}}$ areas.

MICROSCOPIC EXAMINATION (Figs. 2, 3, and 4) The tumour was composed of well-differentiated irregular $\mathbb{D}$ tubular structures surrounded by an undifferentiated $\stackrel{?}{-}$ mesenchyme consisting of fairly uniform plump 0 oval or spindle-shaped cells in a loose matrix. The $\stackrel{0}{P}$ tubular struetures were lined by one or more layers $\overparen{D}$ of hyperchromatic cells. Scattered mitotic figures $\frac{O}{\mathbb{D}}$ were present. Well-formed cartilage was seen in 2 some parts of the tumour (Fig. 3). The surrounding lung was compressed. 


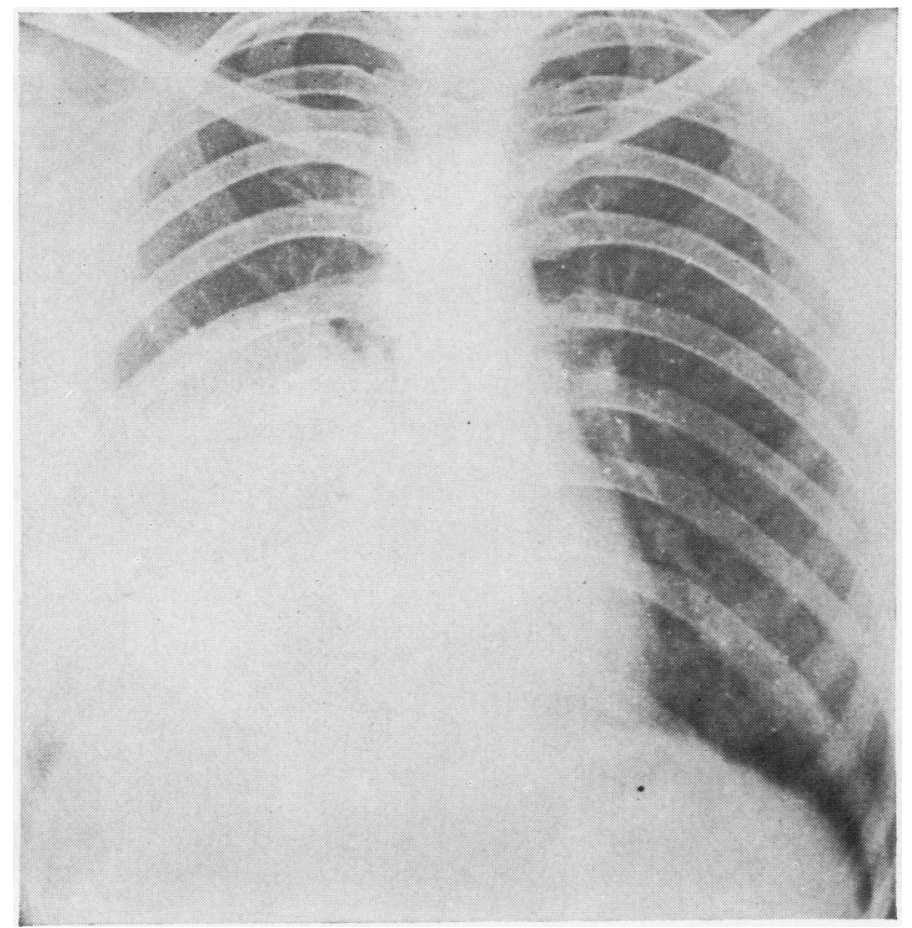

FIG. 2. Low-power view of the tumour showing undifferentiated stroma together with epithelial-lined tubes. In places a merging of the two components can be seen. $H$ and $E \times 68$. 


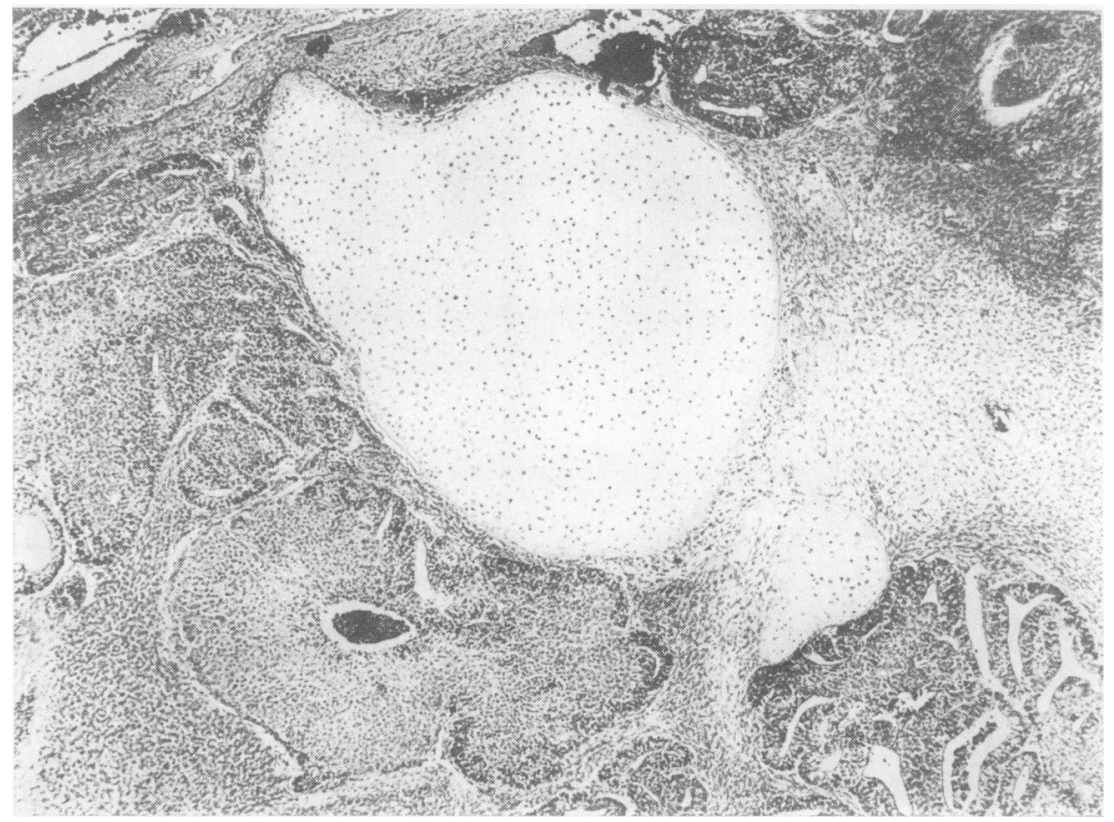

FIG. 3. A low-power view of the tumour showing an island of cartilage together with undifferentiated stroma and some epithelial-lined tubes developing from stroma. $H$ and $E \times 68$.

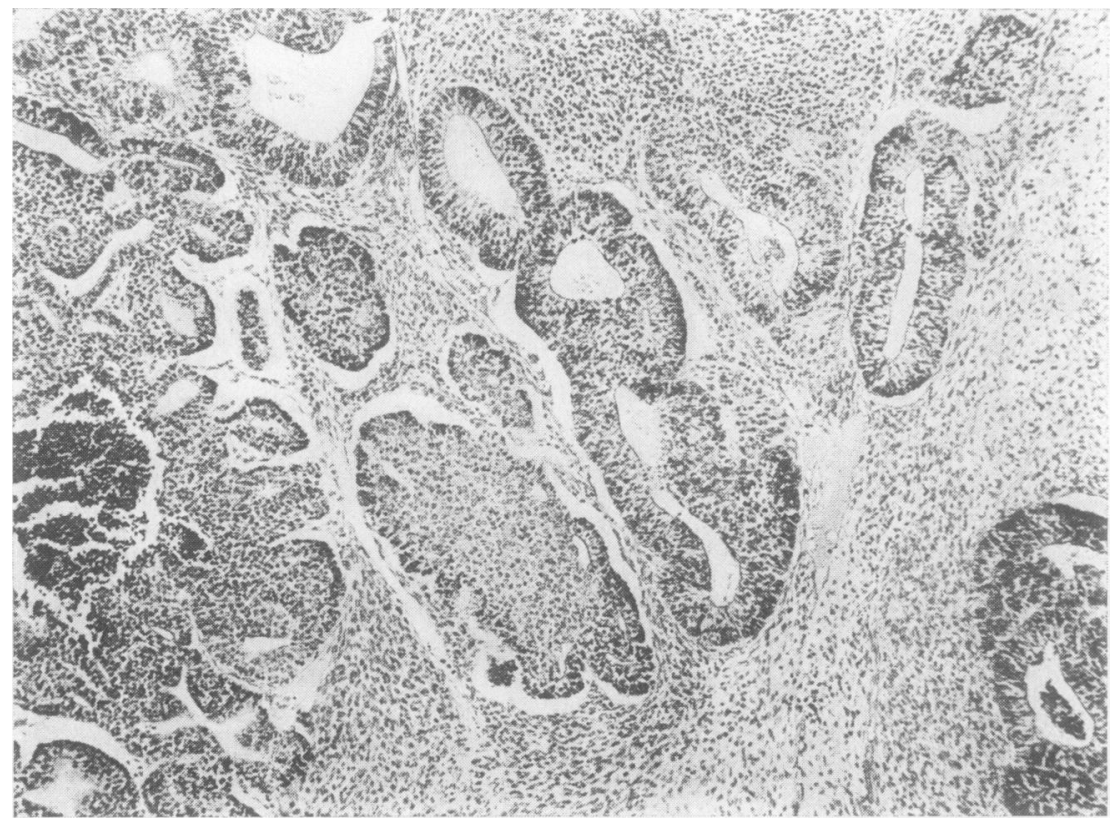

FIG. 4. Epithelial-lined tubes developing by canalization of islands of undifferentiated small round cells. Condensation of the surrounding stromal cells is also shown and these blend with the islands of small round cells. $H$ and $E \times 150$. 


\section{DISCUSSION}

Pulmonary blastoma is a rare tumour and only 19 cases are reported in the world literature (Cox, Fuson, and Daly, 1970). The commonest clinical presentation was with cough and haemoptysis (9 out of 13 cases). Three cases had no symptoms and in one, symptoms were due to cerebral metastases (Cox et al., 1970). Preoperatively, diagnosis is difficult. Chest radiographs, sputum cytology, and bronchoscopy are usually unrewarding. In the present case an initial clinical diagnosis of hydatid cyst was made from the chest film. However, a comparison with the previous film showed a rapid increase in size and this suggested the possibility of a tumour. It is interesting that in the first case reported by Barnard (1952), the clinical diagnosis was hydatid cyst. The definitive diagnosis was made after surgical excision.

The size of the lesion varies from $2.5 \times 2.5$ to $20 \times 26 \mathrm{~cm}$. The size bears no positive relation to long-term survival. The behaviour of the tumour is variable. The longest survival reported after resection is 15 years and the shortest is three months. The average age was 48 years, the range being 19 to 74 years (Cox et al., 1970).

The histogenesis of this tumour is controversial. Spencer (1961) pointed out the close resemblance of the tumour to nephroblastoma and suggested that pulmonary blastomas are derived in an analogous manner from the mesenchymal blastema. This view is supported by the work of Waddell (1949), who showed that the peripheral part of the lung probably develops entirely from pluripotential mesoderm by a process of cell aggregation and canalization to form the distal air passages and alveoli, which then communicate with the more proximal bronchiolar terminations. The presence of well-developed cartilage in the tumour provides additional evidence for the 'blastematous' origin of these tumours. However, Souza, Peasley, and Takaro (1965), Bauermeister, Jennings, Beland, and Judson (1966), and Stackhouse, Harrison, and Ellis (1969) have classified these tumours as a type of carcinosarcoma. According to Nazari, Amir-Mokri, Sarram, and Yaghmai (1971), there is a difference between carcinosarcoma and pulmonary blastoma, the carcinosarcoma arising from two germ layers whereas a blastoma develops from pluripotential cells of a single germ layer. This is supported by the fact that in the majority of carcinosarcomas the epithelial component is squamous-cell carcinoma (Chaudhuri, 1971).

There is no single large experience describing the management of these cases. From the various reports it appears that surgical resection is the treatment of choice. Radiotherapy has been used as a mode of treatment, in some cases for metastases as well as for the primary tumour. This method of treatment was found to be effective in some cases.

\section{REFERENCES}

Barnard, W. G. (1952). Embryoma of lung. Thorax, 7, 299. Bauermeister, D. E., Jennings, E. R., Beland, A. H., and Judson, H. A. (1966). Pulmonary blastoma, a form of carcinosarcoma. American Journal of Clinical Pathology, 46, 232.

Chaudhuri, M. Ray (1971). Bronchial carcinosarcoma. Journal of Thoracic and Cardiovascular Surgery, 61, 319.

Cox, J. L., Fuson, R. L., and Daly, J. T. (1970). Pulmonary blastoma: A case report and review of the literature. Annals of Thoracic Surgery, 9, 364.

Nazari, A., Amir-Mokri, E., Sarram, A., and Yaghmai, I. (1971). Pulmonary blastoma. Chest, 60, 187.

Souza, R. C., Peasley, E. D., and Takaro, T. (1965). Pulmonary blastomas; a distinctive group of carcinosarcomas of the lung. Annals of Thoracic Surgery, 1, 259.

Spencer, H. (1961). Pulmonary blastomas. Journal of Pathology and Bacteriology, 82, 161.

Stackhouse, E. M., Harrison, E. G., and Ellis, F. H. (1969). Primary mixed malignancies of lung: carcinosarcoma and blastoma. Journal of Thoracic and Cardiovascular Surgery, 57, 385.

Waddell, W. R. (1949). Organoid differentiation of the fetal lung. Archives of Pathology, 47, 227. 